\title{
O FEMINISMO EM DICIONÁRIOS DE LÍNGUA PORTUGUESA: UMA ABORDAGEM DISCURSIVA
}

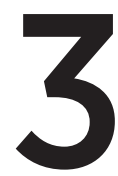

FEMINISM IN PORTUGUESE DICTIONARIES: A DISCURSIVE APPROACH

\section{SILVA, Marianna Lima da}

Mestranda em Estudos Linguísticos (PPGEL/UNESP-SJRP)

\section{GALLI, Fernanda Correa Silveira}

Doutora em Estudos Linguísticos (UNESP-SJRP/PNPD-CAPES)

Pós-doutora em Ciência da Informação e Comunicação (USP-FFCLRP/FAPESP) Professora dos Programas de Pós-graduação em Estudos Linguísticos (PPGEL/ UNESP-SJRP) e em Linguística (PROLING/UFPB)

\section{RESUMO}

A palavra feminismo tem circulado, de forma recorrente, nos discursos das mídias e das redes sociais. A partir da discursivização, mas não só, de que o feminismo não é bem compreendido pela população, optamos por analisar esse verbete (feminismo) pela perspectiva da Lexicografia Discursiva (Orlandi, 2000; Nunes, 2008 e Pontes e Santos, 2014) em dois diferentes dicionários: o Houaiss (2009) - na versão impressa, e o Dicio - na versão online. O primeiro, porque é uma das obras lexicográficas mais consagradas da nossa língua; o segundo, porque acreditamos ser um dicionário bastante acessado e/ou consultado, uma vez que é a primeira indicação do site de buscas Google. Nossa análise considera os elementos e a ordem de sua apresentação na microestrutura de cada um dos verbetes e as definições acompanhadas de suas abreviações e seus exemplos (em alguns casos). Notamos que, embora o texto lexicográfico seja visto por muitos teóricos como neutro e imparcial, ele se configura como discurso, atravessado por uma formação ideológica e suas condições de produção.

Palavras-chave: dicionário; feminismo; discurso; formação ideológica. 


\section{ABSTRACT}

The word feminism has recurrently circulated in the discourses on media and social networks. From the discursivization, but not only, that feminism is not well understood by the population, we've chosen to analyze this headword (feminism) from the perspective of Discursive Lexicography (Orlandi, 2000; Nunes, 2008 and Pontes and Santos, 2014) in two different Portuguese dictionaries: Houaiss (2009) - in the printed version, and Dicio - in the online version. The first one, because it is one of the most renowned Portuguese lexicographic works; the second one, because we believe it is widely accessed and/ or consulted, since it is Google's first indication when you ask for "online dictionary" in Portuguese. Our analysis considers the elements and their order of presentation in the microstructure of each of the entries and the definitions with their abbreviations and their examples (in some cases). We noticed that, although the lexicographic text is seen by many theorists as neutral and impartial, it configures itself as discourse, crossed by an ideological formation and its conditions of production.

Keywords: dictionary; feminism; discourse; ideological formation.

\section{CONSIDERAÇÕES INICIAIS}

Nos últimos anos, feminismo é uma palavra que tem aparecido cada vez mais no discurso não só de mulheres engajadas com o movimento, mas também de homens e de mulheres não engajadas, já que "se trata de um fenômeno que ainda vivemos de forma muito presente e sobre o qual ninguém, homens ou mulheres, nas últimas décadas, ficou imune a ter uma opinião" (PINTO, 2003, p. 9). Por ser assunto recorrente nas mídias sociais, tem sido notícia também nas manchetes de jornais e revistas de grande circulação nacional e internacional, o que se deve, em grande medida, ao ressurgimento do movimento feminista, cujo objetivo primeiro é a equiparação dos direitos das mulheres e dos homens. Conforme resumem Pontes e Santos (2014), a mulher passou a ter maior visibilidade social após a II Guerra Mundial, ao se inserir, gradativamente, no mercado de trabalho. Essa inserção, entretanto, não parece suficiente para que se alcancem direitos iguais, principalmente no que se refere à equiparação salarial. Além disso, a tripla jornada - emprego, casa e filhos - ainda é enfrentada por muitas mulheres, embora alguns homens, mesmo que lentamente, estejam também assumindo esses papéis. Esse panorama 
social é o pano de fundo para o ressurgimento do termo feminismo na contemporaneidade, nas mais diversas esferas da sociedade, e as contribuições desse movimento têm se mostrado cruciais.

Dentre os contextos em que o termo aparece, nos chama atenção o discurso de que o feminismo é mal compreendido. E o que é feminismo, afinal? Como ele pode ser definido? Rocha (2015) afirma que "a palavra, uma vez registrada nas páginas de um dicionário, torna-se pública, oficial e legítima" e que ninguém discorda desta obra tão respeitada. Considerado como o lugar que "guarda" o léxico da língua de uma sociedade, na forma de uma verdade coletiva, o dicionário ocupa, para uma comunidade linguística, um lugar normativo e, portanto, de prestígio. Além disso, e por isso, essa obra lexicográfica é vista como neutra e imparcial. Porém, de acordo com Rey (1977 apud Krieger, 1995), o dicionário é uma obra falsamente natural, um produto falsamente neutro da reflexão linguística. Segundo Andrade, Carvalho e Zambrano (2017), as informações apresentadas em um dicionário podem revelar preconceitos e ideologias que não são percebidos a priori, mas que estão lá, carregados de significados que identificam a sociedade que utiliza aquela língua. Orlandi (2000) propõe a Lexicografia Discursiva, que enxerga na lexicografia, ciência que se dedica ao tratamento e à inserção das unidades lexicais de uma língua nos materiais lexicográficos, discursos, textos produzidos em certas condições de produção, atravessados pela formação discursiva e ideológica em que o lexicógrafo está inscrito.

Neste artigo, com base nos trabalhos de Orlandi (2000), Krieger (1995), Nunes (2008) e Pontes e Santos (2014), buscamos analisar, sob o viés da Lexicografia Discursiva, o verbete feminismo em dois dicionários distintos, um analógico - em versão impressa, e outro eletrônico - em versão online. Optamos por fazer uma comparação em dicionários de suportes distintos justamente para analisar como as diferenças próprias do suporte de divulgação (se houver) podem afetar a definição dos sentidos do termo feminismo que cada um deles apresenta. Além disso, dadas as atuais condições de produção das tecnologias de informação e comunicação, entendemos que a busca por definições de palavras na internet tem sido muito mais recorrente do que a consulta ao dicionário impresso, embora os dicionários eletrônicos online ainda não sejam consagrados como os grandes dicionários impressos analógicos.

Para análise do verbete em suporte analógico, elegemos o impresso Dicionário Houaiss da língua portuguesa (2009) em sua última versão. O critério de escolha dessa obra lexicográfica foi, única 
e exclusivamente, por ser ele um dos dicionários mais reconhecidos da nossa língua. Para análise do verbete em meio digital, elegemos o Dicio - Dicionário Online de Português ${ }^{1}$, um dicionário que, apesar de pertencer a uma empresa lusitana (7Graus) ${ }^{2}$, tem extensão .br, ou seja, está virtualmente alocado no Brasil, e apresenta conteúdo relativo ao português brasileiro. O critério de escolha dessa obra foi a indicação de resultado do Google: ao digitarmos nesse site de busca "dicionário online", a primeira opção que nos é oferecida é o Dicio, o que nos leva a crer que ele deve ser bastante consultado. O trabalho está dividido em Fundamentação Teórica, $\mathrm{O}$ feminismo em dicionários de língua portuguesa e Considerações Finais. Nosso objetivo não é apenas demonstrar como o verbete feminismo é construído nos dicionários ou como ele é definido, mas analisar como os domínios que compõem a microestrutura desse verbete bem como suas condições de produção são capazes de apontar a ideologia que atravessa esses discursos, considerados, equivocadamente, como neutros.

\section{FUNDAMENTAÇÃO TEÓRICA}

O léxico de uma língua, segundo Andrade, Carvalho e Zambrano (2017), é composto por palavras e expressões utilizadas pelos falantes dessa língua nas várias situações de comunicação, e o estudo dos elementos que compõem esse léxico é relevante para a compreensão das escolhas feitas pelos falantes e da cultura e da ideologia presentes na língua, que são percebidas nesses elementos. Dentre as ciências do léxico, responsáveis pelo estudo dos elementos lexicais, a Lexicografia é a que se debruça ao tratamento e à inserção dessas unidades em materiais lexicográficos, a saber, os dicionários, os glossários e as listas de palavras, que podem ser classificadas quanto aos usuários aos quais se destinam e quanto ao suporte de publicação. Em relação ao público-alvo, um dicionário pode ser classificado em: de língua geral, de aprendizagem, escolar, especial e especializado; e, em relação ao suporte, pode ser analógico (impresso) ou eletrônico (online e off-line), segundo a classificação de Pontes (2009, apud Andrade, Carvalho e Zambrano, 2017).

Conforme defende Krieger (1995, p. 216), os dicionários de uma determinada língua constituem textos de natureza metalinguística que assumem funções didáticas e desempenham um importante papel na história das línguas, principalmente como "instrumentos reguladores da manutenção e da mudança dos universos lexicais". Esse material,

1. Disponível em: <https://www.dicio.com.br/>. Acesso em: 18 out 2018.

2. Disponível em: <https://www.7graus.com/portfolio/>. Acesso em: 18 out 2018. 
especificamente, é constituído em instâncias formais de legitimação do léxico e, portanto, possui um estatuto de poder na sociedade em que está inserido. Ao serem consultados, são vistos como detentores da verdade das palavras, uma verdade coletiva - e não individual -, já que são reconhecidos por se limitar à reprodução dos usos e dos sentidos consagrados pelas relações léxico e cultura.

Pontes (2009 apud Andrade, Carvalho e Zambrano, 2017) afirma que, apesar de não possuírem uma definição formal, os conceitos de léxico e cultura podem ser aproximados. O léxico, entendido como o conjunto de palavras de uma língua e suas propriedades, abrange seus aspectos fonológicos, morfológicos e semânticos. Porém, mais do que isso, o léxico "constitui-se no acervo do saber vocabular de um grupo sócio-linguístico-cultural", nível esse que mais deixa transparecer os valores, as crenças, os hábitos e os costumes de uma comunidade, assim como suas transformações socioeconômicas e políticas. (PIRES DE OLIVERIRA, ISQUERDO, 2001, p. 9 apud PONTES e SANTOS, 2014, p. 126). Para o autor,

o léxico de uma comunidade não só deixa transparecer suas características culturais como também contribui para a formação e manutenção das mesmas numa relação dialética. Portanto, os usos que uma comunidade faz da linguagem são representativos de sua cultura, aqui entendida como os valores, crenças e costumes de um grupo sociocultural, bem como sua organização social e política (PONTES, 2009, p. 127 apud ANDRADE, CARVALHO E ZAMBRANO, 2017).

Ele ressalta, ainda, a posição privilegiada que as obras lexicográficas ocupam em uma sociedade, uma vez que recorremos a um dicionário sempre que queremos compreender o significado de uma palavra em determinado contexto, ou averiguar sua ortografia, ou verificar se existe uma flexão irregular em determinado verbo. Embora não sejam os únicos, esses usos evidenciam a configuração do dicionário como uma autoridade nas questões de linguagem, ratificando seu status privilegiado. Ainda segundo o que defendem Pontes e Santos (2014), a compilação e a organização das palavras da língua, contemplando um grande número de entradas, tornam o dicionário um artefato cultural, um recorte da cultura de uma comunidade em um determinado período histórico.

É por isso que Krieger (1995, p. 216) defende que o lexicógrafo "costuma ser reconhecido como detentor potencial de um saber 
linguístico profundo sobre o funcionamento gramatical e semântico de uma língua", mantendo uma posição de sujeito do saber, um saber inquestionável, aceito como verdadeiro e imparcial. Porém, é importante lembrar que, conforme afirmam Pontes e Santos (2014, p. 128), "todo dicionário é fruto da reflexão de um membro de uma comunidade sociolinguística sobre os usos de sua própria língua", reflexão essa não tão imparcial como se demonstra, mas atravessada pela ideologia que constitui esse sujeito lexicógrafo e a posição que ele ocupa na sociedade. O autor menciona a pesquisa realizada por Humblé (2002) sobre imparcialidade de produtos lexicográficos produzidos com auxílio de ferramentas da informática que aponta para a influência do lexicógrafo na análise do corpus que embasa a elaboração dos produtos lexicográficos que seguem os preceitos da Lexicografia moderna.

Nessa mesma direção, Orlandi (2000, p. 97) postulou a Lexicografia Discursiva, que vê discursos nos dicionários, ou seja, considera-os "textos produzidos em certas condições, tendo o seu processo de produção vinculado a uma determinada rede de memória ante a língua". Segundo a autora, o dicionário se organiza ideologicamente de uma determinada maneira, respeitando uma estrutura geral: indicação da categoria, da pronúncia, da escrita e dos sentidos, em geral organizados com base em um principal, que seria o literal, e suas variações.

Não se olha o dicionário, porém, a partir de como os sentidos das palavras estão em processo, ou de como elas se distribuem, significando diferentemente, de acordo com as diferentes formações discursivas ${ }^{3}$, que correspondem a diferentes posições do sujeito, ante a ideologia, isto é, "o dicionário silencia sobre o fato de que não há palavra, não há sentido, sem ideologia" (ORLANDI, 2000, p. 101). No dicionário, "a língua aparece como 'nossa' língua, a língua 'comum', dos 'brasileiros'" ORLANDI, 2000, p. 102). Esse material oferece ao consulente uma língua aparentemente homogênea, perfeita, completa e sem falhas, constituindo-se como "neutro", sem marcas ideológicas; porém, como defende autora, sempre é possível ver neles os vestígios da

3. A noção de formação discursiva (FD), formulada inicialmente por Foucault, pode ser definida quando "se puder descrever, entre um certo número de enunciados, semelhante sistema de dispersão, e no caso em que entre os objetos, os tipos de enunciação, os conceitos, as escolhas temáticas, se puder definir uma regularidade (uma ordem, correlações, posições e funcionamentos, transformações)..." (FOUCAULT, 2002, p.35). Já Pêcheux (1997), a partir da noção apresentada por Foucault, destaca que as formações discursivas estão relacionadas diretamente com as formações ideológicas e, assim, determinam "o que pode e deve ser dito (articulado sob a forma de uma arenga, de um sermão, de um panfleto, de uma exposição, de um programa, etc.) a partir de uma posição dada numa conjuntura dada: o ponto essencial aqui é que não se trata apenas da natureza das palavras empregadas, mas também (e sobretudo) de construções nas quais essas palavras se combinam [...] as palavras 'mudam de sentido' ao passar de uma formação discursiva a outra" (p.160) 
presença da ideologia, a começar pelo próprio prefácio, tratado como um gênero discursivo cuja análise, segundo Nunes (2008), permite compreender a imagem da língua, do dicionário e do público leitor concebida pelo lexicógrafo. $\mathrm{O}$ autor destaca que, em Lexicografia, o texto do dicionário é, normalmente, dividido entre o que se considera a macroestrutura, ou seja, o conjunto de entradas e subentradas, e a microestrutura, os domínios que compõem o verbete: marcação gramatical, definição, exemplos, etimologia etc.

Segundo Nunes (2008), o estudo das definições dos dicionários pelo viés discursivo é muito produtivo. Ele destaca o estudo de Collinot e Mazière (1997 apud NUNES, 2008), que demonstrou, por exemplo, que certas definições, quando não apresentam um sujeito atuante, produzem um efeito de naturalidade, enquanto outras, quando apresentam um sujeito atuante, produzem um efeito de sociedade, por incluírem esses sujeitos na cena enunciativa. Além disso, para o autor, os exemplos, quando introduzidos, se mostram como a marca mais visível de ideologia ${ }^{4}$. Sobre isso, Pontes e Santos (2014) afirmam que os exemplos revelam a intertextualidade que caracteriza os textos lexicográficos, ao fazerem referências a outros textos, ou partes de textos, provenientes de diferentes gêneros que circulam na sociedade e representam diferentes práticas sociais, o que revela, também, o entrecruzamento de diferentes vozes no discurso lexicográfico, evidenciando seu caráter polifônico. Os autores destacam, ainda, que esse entrecruzamento não ocorre de forma aleatória, já que o lexicógrafo é uma peça importante na elaboração do dicionário, exercendo grande influência sobre o produto final.

Andrade, Carvalho e Zambrano (2017) enfatizam que o texto contido em um dicionário, apesar de ser considerado "neutro", pode revelar preconceitos e ideologias que, geralmente, passam despercebidos, mas revelam significados que identificam a sociedade que utiliza a língua. Portanto, sob a ótica da perspectiva teórica da Lexicografia Discursiva, analisamos, nesta abordagem, o verbete feminismo em dicionários analógicos e eletrônicos (online), procurando compreender os verbetes na relação com os discursos que os constituem, considerando não só suas marcas linguísticas, mas também suas condições de produção.

4. Ancorada nas reflexões de Pêcheux (1997), Orlandi aponta que "a ideologia faz parte, ou melhor, é a condição para a constituição do sujeito e dos sentidos" e o seu trabalho, o da ideologia, é "produzir evidências, colocando o homem na relação imaginária com suas condições materiais de existência” (2001, p.46). 


\section{O FEMINISMO EM DICIONÁRIOS DE LÍNGUA PORTUGUESA}

A partir desses pressupostos teóricos, analisamos o verbete feminismo em dicionários gerais, isto é, aqueles que contêm "as palavras que podem ser usadas em qualquer contexto discursivo" (PONTES, 2009 apud ANDRADE, CARVALHO E ZAMBRANO, 2017, p. 436), são sincrônicos, da língua contemporânea e apresentam os lexemas da língua comum (WELKER, 2004 apud ANDRADE, CARVALHO E ZAMBRANO, 2017). Nosso objetivo é fazer uma comparação entre dicionários analógico (impresso), por ser consagrado, e eletrônico (online), por ser bastante acessado. $\mathrm{O}$ dicionário analógico que elegemos é o Dicionário Houaiss da língua portuguesa (2009), em sua última versão, revista após o novo acordo ortográfico, por ser este um dos dicionários mais consagrados da nossa língua atualmente. Quanto ao formato eletrônico, optamos por analisar o verbete feminismo apresentado pelo Dicio - Dicionário Online de Português, um dicionário pertencente a uma empresa portuguesa, porém em domínio brasileiro da internet, com extensão .br, por ser a primeira opção oferecida pelo popular site de busca Google. Embora o Dicionário Houaiss da língua portuguesa seja bastante consagrado, acessá-lo não é tão fácil e rápido como é acessar o Dicio - Dicionário Online de Português, que, por sua vez, não é tão consagrado quanto o impresso.

Para nossa análise, selecionamos, em ambos os dicionários, o verbete feminismo, e consideramos o padrão estabelecido para a apresentação da microestrutura - quais elementos são apresentados e em que ordem -, bem como as definições acompanhadas das abreviações e dos exemplos. Os demais elementos que compõem esses verbetes nos referidos dicionários, não foram considerados. Como já mencionamos, o Houaiss (2009) é um dos dicionários de Língua Portuguesa mais consagrados na atualidade e, nele, o verbete feminismo se apresenta como segue:

feminismo s.m. (1905) $\mathbf{1}$ doutrina que preconiza o aprimoramento e a ampliação do papel e dos direitos das mulheres na sociedade. 2 p.met. movimento que milita nesse sentido. 3 p.ext. teoria que sustenta a igualdade política, social e econômica de ambos os sexos. 4 p.met. atividade organizada em favor dos direitos e interesses das mulheres. 5 interesse do homem pela mulher; atração. $\mathbf{6}$ MED p.us. presença de caracteres femininos no homem * ETIM fr. fèminisme (1837) 'doutrina que visa à extensão dos papéis femininos' (HOUAISS, 2009, p. 885). 
Nesse dicionário, respectivamente, temos a seguinte estrutura geral: palavra de entrada; informação gramatical; ano em que a palavra foi registrada pela primeira vez na língua portuguesa; definição, precedida de abreviação ou seguida de exemplo de uso (quando é o caso); etimologia; datação da palavra na língua de origem; e, por fim, definição na língua de origem. O padrão determinado para essa microestrutura nos parece bastante lógico, porém não tão simples. Algumas informações apresentadas são bastante específicas e vão além da simples consulta pelo significado da palavra, como é o caso da datação, tanto do registro da palavra na língua portuguesa, quanto da palavra na língua de origem. Além disso, as abreviações que precedem algumas definições na microestrutura de feminismo podem não ser evidentes de pronto ao consulente, que necessitará consultar a lista de abreviaturas do dicionário para entender do que se trata. Essa organização ratifica o fato de que o leitor concebido pelos lexicógrafos - aqueles que trabalharam na elaboração do dicionário refere-se a alguém que já tem um bom domínio da língua portuguesa e da prática de consulta de dicionários. Das informações apresentadas na microestrutura, nos restringiremos às definições e aos exemplos apresentados, conforme já sinalizamos.

O verbete apresenta cinco acepções - marcadas pela numeração em negrito, nenhuma delas com exemplo de uso -, sobre as quais nos deteremos na análise. Da primeira acepção ("1 doutrina que preconiza o aprimoramento e a ampliação do papel e dos direitos das mulheres na sociedade."), recortamos os significantes aprimoramento e ampliação, os quais sinalizam que a mulher já possui direitos, e que, segundo essa "doutrina", eles devem ser aprimorados e ampliados, o que parece produzir um efeito de reivindicação. Sobre esse aspecto, Cestari (2010, p. 787) aponta que o movimento feminista sempre teve forte relação com os partidos de esquerda: "o feminismo brasileiro dos anos 1970 expandiu-se através de uma articulação política peculiar com os movimentos populares que tinham participação expressiva de mulheres, tornando as demandas femininas das organizações de bairro próprias do movimento geral das mulheres brasileiras". Embora a ideia de "direitos das mulheres" apareça, logo nessa primeira acepção, a proposta de uma relação de igualdade em relação aos direitos que são concedidos aos homens, por exemplo, é silenciada. Além disso, a palavra "doutrina", aqui, nos parece atravessada pela ideologia conservadora, que faz emergir o entendimento sobre feminismo como uma "norma" e retoma, pela memória discursiva ${ }^{5}$, "a ordem

\footnotetext{
5. De acordo com Pêcheux (2007, p.52), a memória discursiva "seria aquilo que, face a um texto que surge como acontecimento a ser lido, vem restabelecer os 'implícitos' (quer dizer, mais tecnicamente, os pré-construídos, elementos citados e relatados, discursos-transversos, etc.) de que sua leitura necessita: a condição do legível em relação ao próprio legível.".
} 
conservadora que excluía a mulher do mundo público - portanto, dos direitos como cidadão - e também as propostas revolucionárias, que viam na luta das mulheres um desvio de pugna do proletariado por sua libertação", tal como destaca Pinto (2003, p.9).

A segunda acepção ("2 p.met. movimento que milita nesse sentido.") é precedida da abreviação p. met., por metonímia, o que significa dizer que o feminismo empregado como "movimento", que milita pelo aprimoramento e pela ampliação do papel e dos direitos das mulheres na sociedade, é empregado fora de seu contexto semântico "normal". Essa definição revela que o feminismo não é normalmente entendido como um "movimento", também no sentido metonímico de "partido, agrupamento, organização que vise a mudanças políticas ou sociais", tendo sua concepção mais forte como doutrina. Novamente, emerge a reivindicação, a relação com a luta - "pela igualdade de trabalho, pelo fim do machismo, pela maternidade livre, pelo orgasmo livre, pelo fim da violência, pelo fim da transfobia, bifobia e da lesbofobia, pelo fim do racismo" (GARCIA; SOUSA, 2014, p.1053), com a busca pelo respeito e pelo lugar de cidadã, de maneira que a militância caracteriza o que é ser mulher, o que é ser feminista, o que é ser livre.

Já a terceira acepção ("3 p.ext. teoria que sustenta a igualdade política, social e econômica de ambos os sexos.") é precedida pela abreviação $p$. ext., por extensão de sentido, o que significa dizer que a primeira definição é a "original" do termo e que aquela a ser apresentada derivou semanticamente desta primeira. Ou seja, nesse caso, significa que o feminismo visto como teoria está mais próximo da ideia de doutrina ("que sustenta") do que o feminismo visto como movimento, por exemplo. É interessante observar que apenas nessa acepção a ideia de igualdade é apresentada: fala-se em "igualdade política, social e econômica de ambos os sexos", mas não se explicita a ideia de igualdade de direitos políticos, sociais e econômicos. O que exatamente significa a igualdade social de ambos os sexos? Igualdade em relação àquilo que está previsto em lei, ou em relação ao que é convenção social? Evidencia-se, aqui, a busca pela neutralidade na obra lexicográfica que, ao contrário disso, demonstra um distanciamento da "causa/luta feminista": primeiro, por relacionar o aspecto da busca pela igualdade ao termo teoria, se aproximando mais de conceitos do que de práticas; segundo, por não definir exatamente a que tipo de igualdade se refere.

Por fim, a quarta acepção - e última que nos interessa para essa análise ("4 p.met. atividade organizada em favor dos direitos e interesses das mulheres.") - apresenta um conceito também precedido 
da abreviação que indica um significado atribuído por metonímia, ou seja, fora do seu contexto semântico "normal". Ao sinalizar que o feminismo atua "em favor" das mulheres, essa acepção faz vir à tona o sentido de que a "atividade" feminista opera contra os homens, contra o que é garantido social e historicamente à posição masculina, contra o que é discursivizado como benefício para a pessoa do sexo masculino, questões que, portanto, parecem reforçar a desigualdade de gêneros. De nosso ponto de vista, trata-se de uma visão legitimada sobre a posição das mulheres feministas na sociedade, a qual é da ordem do conservadorismo, da violência simbólica de gêneros e do silenciamento.

Do modo como foram apresentadas as acepções, é possível perceber uma aproximação entre "doutrina" e teoria", que se distanciam de "movimento" e "atividade", também com seus sentidos aproximados. Isto é, de um lado, apresentam-se sentidos que se referem ao feminismo como conceito (doutrina e teoria) e, de outro, apresentam-se sentidos que se referem ao feminismo como prática (movimento e atividade), mas não numa relação de equivalência. Os sentidos mais conceituais do termo feminismo têm mais força nessa obra lexicográfica, considerando que a primeira acepção apresentada é "doutrina" e é esta definição conceitual mais "forte" (inclusive em relação à "teoria"). "Movimento", a definição que apresenta o sentido mais prático ao termo, é mais "forte" do que "atividade", mas ambos são apresentados como sentidos metonímicos, o que os enfraquece em relação aos outros dois sentidos apresentado, ratificando, junto a todas as outras questões apresentadas, o caráter mais conservador do dicionário, embora o fato de esses sentidos estarem intercalados nessa microestrutura (doutrina; movimento; teoria; atividade) pareça um artifício utilizado pelo lexicógrafo para (tentar) neutralizar a formação ideológica em que ele está inscrito.

Passamos, a seguir, para a análise do verbete feminismo no Dicio - Dicionário Online de Português, o dicionário eletrônico online que também elegemos para esse estudo. A microestrutura, nesse caso, apresenta um layout bastante diferente de um verbete de um dicionário analógico (impresso), conforme apresentado (parcialmente) na imagem a seguir: 
Figura 1: Layout parcial da entrada de feminismo no Dicio $^{6}$ )

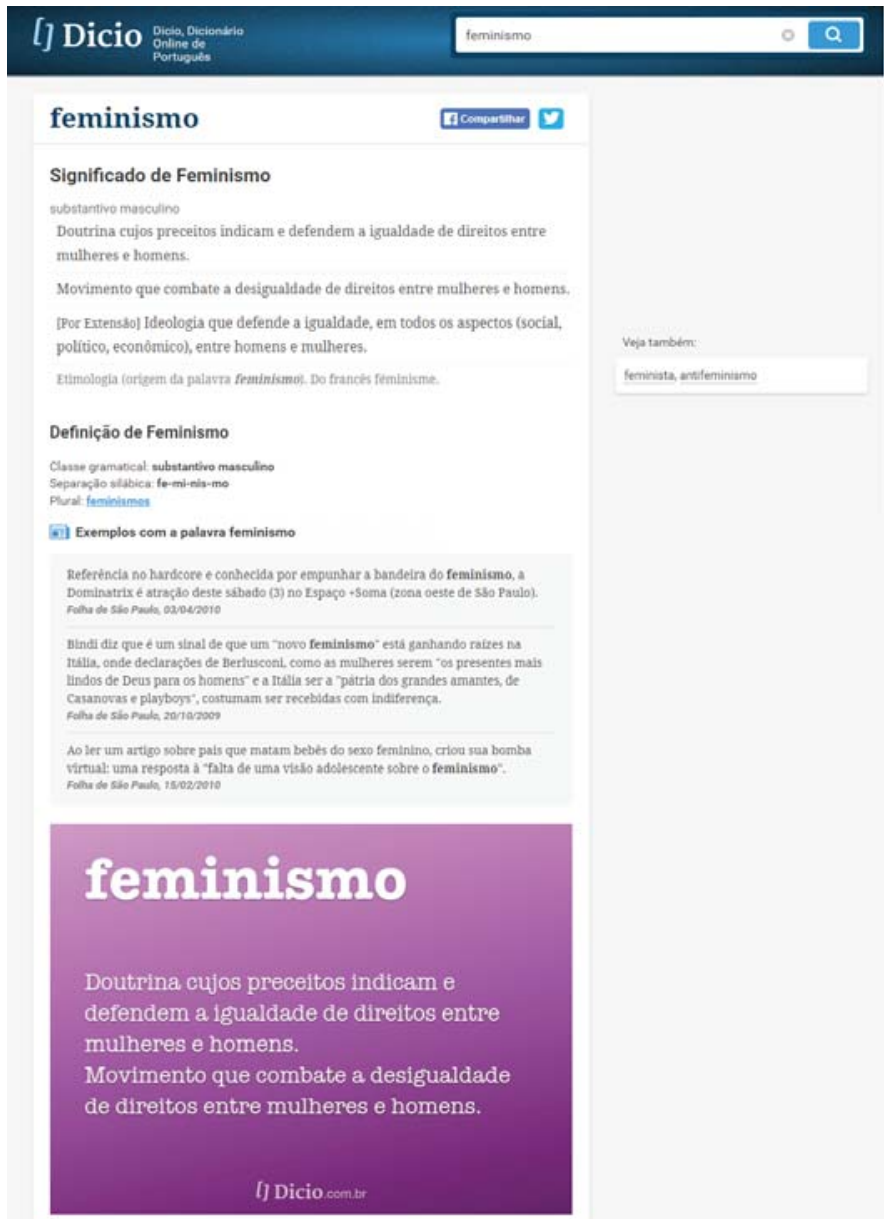

No formato online, o layout se difere, em muito, do modo como se apresentam os verbetes no dicionário analógico. Apesar da diferença visual, a padronização não se altera muito se comparada à mais usual nos dicionários impressos. Como podemos observar, nesse caso, o verbete apresenta, respectivamente, a seguinte estrutura geral: palavra de entrada; subtítulo que indica o significado do verbete e os três significados em sequência; etimologia da palavra; subtítulo que indica a definição do verbete seguido de informações gramaticais do termo (classe gramatical, separação silábica e plural, respectivamente);

6. https://www.dicio.com.br/feminismo/ 
exemplos com a palavra feminismo; um quadro destacado de resumo, com as duas primeiras definições; outras informações sobre a palavra (número de letras, indicações das vogais, das consoantes e palavra escrita ao contrário); e, por fim, rimas com a palavra feminismo. Como dissemos, o layout foi apresentado parcialmente, já que os últimos elementos da estrutura geral dessa microestrutura (outras informações sobre a palavra e rimas com a palavra feminismo) não nos interessam para essa análise.

Apesar de apresentar um padrão consideravelmente semelhante, à microestrutura do mesmo verbete no dicionário analógico que analisamos, em relação aos elementos que a compõem e a ordem em que esses elementos aparecem, essa microestrutura é nitidamente mais simples. Embora também apresente informações específicas sobre a palavra, essas (separação silábica, número de letras, indicação das vogais e das consoantes) são mais simples, menos técnicas do que aquelas apresentadas no dicionário impresso (datação, por exemplo). Esse dicionário também não apresenta abreviações em sua microestrutura, ao contrário, indica o tipo de definição escrito entre colchetes sem abreviá-lo. Essa organização mais simples e direta revela que o leitor pré-concebido pelos lexicógrafos desse dicionário não é alguém que necessariamente tenha um bom domínio da língua portuguesa ou da prática de consulta de dicionários, uma vez que não é necessário ter um bom domínio da língua para consultar dicionários, diferentemente do que revela a organização do verbete do dicionário impresso.

Nossa análise, nesse caso, restringe-se às definições apresentadas e a aos exemplos trazidos pelo dicionário, já que estes ainda contribuem (ou não) para o entendimento das definições e revelam o posicionamento ideológico das elaboradoras da obra lexicográfica. A primeira acepção ("Doutrina cujos preceitos indicam e defendem a igualdade de direitos entre mulheres e homens."), assim como no Houaiss (2009), define o feminismo como uma doutrina, termo que consideramos, a priori, revelar um posicionamento mais conservador. Nesse caso, porém, ao se definir que o feminismo é a doutrina "cujos preceitos indicam e defendem a igualdade de direitos entre mulheres e homens", já se apresenta, de pronto, o conceito de "igualdade" e, aliado a ele, o conceito de "defesa", do campo semântico da luta, o que parece nos revelar um posicionamento atravessado por uma ideologia menos conservadora, que aproxima o conceito do feminismo àquele conceito mais prático. 
A segunda acepção ratifica nossa hipótese, porque apresenta o feminismo como o "Movimento que combate a desigualdade de direitos entre mulheres e homens". Embora também apareça "movimento" como definição de feminismo, nesta acepção, diferentemente do Houaiss (2009), não há qualquer menção à metonímia ou extensão de sentido, o que coloca essa segunda definição quase com a mesma força que a anterior, não fosse o fato de que esta é apresentada primeiro. Mesmo assim, ressalta-se esse caráter mais prático nessa definição com a menção à "combate", também do campo semântico de "luta". Além disso, mais uma vez, o conceito de igualdade de direitos entre mulheres e homens também aparece, dessa vez com mais força, uma vez que não se anuncia a igualdade de direitos como objetivo, mas se indica a desigualdade de direitos como existente.

A terceira e última de acepção é indicada como definida por extensão de sentido em relação à primeira acepção, já que se refere à "Ideologia que defende a igualdade, em todos os aspectos (social, político, econômico), entre homens e mulheres. Por mais que "ideologia", aqui entendida como o conjunto de ideias, se aproxime mais da concepção de "doutrina", ou seja, do caráter teórico do conceito de feminismo, são apresentados nessa definição termos, como "defende" e "igualdade", que, como já mencionamos, se aproximam de um conceito mais prático do feminismo, como "luta pela igualdade". Além disso, nessa acepção, não se omite em relação a que tipo de igualdade se refere o feminismo, ao contrário define-se que essa igualdade é defendida em todos os aspectos: social, político e econômico, revelando, assim, um caráter mais progressista nesse verbete.

Os exemplos apresentados pelo dicionário em questão confirmam nossa hipótese, pois não são eruditos. Apesar de retirados da Folha de S. Paulo, periódico impresso de grande circulação nacional cujo público-alvo é composto, majoritariamente, pela população letrada, os contextos que exemplificam o uso do termo feminismo são bem populares e ratificam essa visão mais progressista, uma vez que fazem emergir o feminismo enquanto luta ("empunhar a bandeira do feminismo") e enquanto um movimento renovado/contemporâneo ("'novo feminismo' está ganhando raízes na Itália" e "uma visão adolescente do feminismo") .

Ao contrário do Houaiss (2009), que distingue conceitos teóricos e práticos do feminismo, distanciando-os e valorizando os conceitos teóricos, no Dicio, do modo como foram apresentadas as acepções e os exemplos, percebemos que o caráter teórico e o prático do feminismo 
estão reunidos em cada acepção. Mais do que isso, no dicionário online, valoriza-se o caráter de "luta", pela escolha de palavras desse campo semântico em todas as definições, e o ressurgimento dessa luta, pela escolha dos exemplos, que ratificam a inscrição do dicionário numa formação ideológica mais progressista do que o Houaiss (2009).

\section{CONSIDERAÇÕES FINAIS}

Após a análise dos verbetes que definem a palavra feminismo - tanto no dicionário impresso, quanto no online, reafirmamos que eles revelam posicionamentos ideológicos distintos, considerando, logo de início, as diferentes condições de produção entre eles - o suporte, principalmente. Enquanto o dicionário impresso revela-se mais conservador em suas definições e nos modos de apresentá-las, o dicionário online apresenta características menos conservadoras e, talvez, mais progressista, embora com ressonâncias que implicam resistências. Essas diferenças não têm relação com os modos distintos de veiculação (impresso e online) dos dicionários, mas se justificam porque o texto lexicográfico é um discurso, como outros, atravessado não só pelas suas condições de produção, mas também pela ideologia, o que vem desmistificar as concepções - ilusórias - de neutralidade e de imparcialidade atribuídas aos textos lexicográficos, justificadas pelos esquecimentos defendidos por Pêcheux (1997), que nos dão a ilusão de que a linguagem é transparente, ou seja, análoga à realidade, e de que somos a origem daquilo que dizemos.

\section{REFERÊNCIAS BIBLIOGRÁFICAS}

ANDRADE, G. O.; CARVALHO, G. L.; ZAMBRANO, R. C. "A representação do gênero em dicionários monolíngues dos idiomas alemão, espanhol e português: uma análise crítica feminista de verbetes referentes às profissões". Calidoscópio, São Leopoldo, v. 15, n. 3, p. 433-442, set/dez 2017. Disponível em: http://revistas.unisinos.br/index.php/calidoscopio/article/view/ cld.2017.153.03/6328. Acesso em: 25 mar.2018.

CESTARI, M. J. Nós político no discurso feminista dos anos 70. Anais do Seta, n. 4, p. 779- 792, 2010.

FEMINISMO. In: HOUAISS, A. VILLAR, M.S. Dicionário Houaiss da língua portuguesa. 1. ed. Rio de Janeiro: Objetiva, 2009. p. 885.

FEMINISMO. In: Dicio, Dicionário online de Português. Disponível em: https://www. dicio.com.br/feminismo/. Acesso em: 15 abr. 2018. 
GARCIA, D. A.; SOUSA, L. M. A. E. A Marcha das Vadias nas redes sociais: um discurso da militância?. Estudos Linguísticos (São Paulo. 1978), v. 43, p. 1041-1055, 2014. Disponível em: https://revistas.gel.org.br/estudos-linguisticos/article/view/504/381. Acesso em: 18 out. 2018.

KRIEGER, M. G. "Da Prática Significante Lexicográfica". Organon. Porto Alegre, v. 9, n. 23, p. 211-220, 1995. Disponível em: http://www.seer.ufrgs.br/organon/article/ download/29377/18065. Acesso em: 25 mar. 2018.

NEVES, M. H. M. A prática lexicográfica: onde ciência e arte se encontram. Alfa, São Paulo, n. 40, p. 129-139, 1996. Disponível em: https://periodicos.fclar.unesp.br/alfa/ article/view/4000/3670. Acesso em 24.03.2018.

NUNES, J. H. Uma articulação da análise de discurso com a história das ideias linguísticas. Letras,SantaMaria, v.18,n.37,2008.Disponívelem:https://periodicos.ufsm.br/letras/article/ view/11982/7396. Acesso em: 24 mar. 2018.

ORLANDI, E. P. Lexicografia Discursiva. Alfa, São Paulo, n. 44, p. 97-114, 2000. Disponível em: https://periodicos.fclar.unesp.br/alfa/article/view/4201/3797. Acesso em: 24 mar. 2018.

ORLANDI, E. P. Análise de Discurso: princípios e procedimentos. 3 ed. Campinas: Pontes, 2001.

PÊCHEUX, M. Papel da memória. In: ACHARD, P. et al. Papel da memória. Trad. e Intr. José Horta Nunes. Campinas: Pontes, 2007. p.49-58.

PÊCHEUX, M. Semântica e discurso: uma crítica à afirmação do óbvio. 3 ed. Campinas: Editora da Unicamp, 1997.

PINTO, C. R. J. Uma história do feminismo no Brasil. São Paulo: Perseu Abramo, 2003.

PONTES, A. L.; SANTOS, H. L. G. "A representação do homem e da mulher no Dicionário de Usos do Português do Brasil". Linha D’Água, São Paulo, v. 27, n. 2, p. 123-140, dez. 2014. Disponível em: https://www.revistas.usp.br/linhadagua/article/view/84308/91666. Acesso em: 24 mar. 2018.

ROCHA, Z. M. D. "O amor e o erótico lexicograficamente analisado: uma visão discursiva". Entrepalavras, Fortaleza, ano 5, v. 5, n. esp., p. 40-49, ago/dez. 2015. Disponível em: http://www.entrepalavras.ufc.br/revista/index.php/Revista/article/ viewFile/575/304. Acesso em: 25 mar. 2018.

Recebido em: 20/10/6/2018

Aceito em: 20/11/2018 